\title{
Causes and characteristics of medical student referrals to a professional behaviour board
}

\author{
Pieter C. Barnhoorn ${ }^{1}$, Jan H. Bolk ${ }^{1}$, Marleen W. Ottenhoff- de Jonge ${ }^{1}$, Walther N.K.A. van Mook ${ }^{2}$, \\ Arnout Jan de Beaufort ${ }^{1}$
}

${ }^{1}$ Department of Public Health and Primary Care, Leiden University Medical Centre, The Netherlands

${ }^{2}$ Department of Intensive Care Medicine, Maastricht University Medical Centre, The Netherlands

Correspondence: Pieter C. Barnhoorn, Department of Public Health and Primary Care, Leiden University Medical Centre, Hippocratespad 21, PO box 9600, Zone V0-P, 2300 RC Leiden, The Netherlands. E-mail: p.c.barnhoorn@lumc.nl

Accepted: December 10, 2016

\begin{abstract}
Objectives: To describe the nature of unprofessional behaviour displayed by medical students, as well as the characteristics of students referred to the professional behaviour board.

Methods: A descriptive mixed methods approach was taken, in which qualitative data on unprofessional behaviour, as well as quantitative data on the demographics of referred students were collected during the study period between June 1, 2009 and January 1, 2014. In order to compare the referred students with the total student population, data on gender, nationality and phase in the curriculum of the total student population, collected from the student administration desk, were also used.

Results: In the study period, a total of 107 referrals were reported, concerning 93 different students (3\% of the total student population). Sixty-five of the 107 referrals (61\%) concerned male students. Thirty referrals $(28 \%)$ concerned non-Dutch students. Most referrals (71\%) occurred during

clinical rotations. The referrals were equally distributed over three professional behaviour domains: dealing with oneself, dealing with others, and dealing with tasks/work. 'Withdrawn behaviour' was reported 17 times, 'insufficient Dutch language proficiency' 14 times, 'impertinent emails' 9 times and 'placing privacy-sensitive photos on the internet' 3 times.

Conclusions: Although only a minority of students are referred to a professional behaviour board, this study shows that student characteristics such as gender and nationality may correlate to a higher incidence of unprofessional behaviour. Further explanatory and exploratory research is needed to unravel this relationship, and to study the influence of curriculum reforms on these relationships, respectively.

Keywords: Professional behaviour, professionalism, professional identity formation, medical students, professional behaviour board
\end{abstract}

\section{Introduction}

Over the past three decades, professionalism has been incorporated as a major theme in most medical curricula. ${ }^{1-3}$ Professionalism is a key competence in the CanMEDS 2015 framework used in both undergraduate and postgraduate medical education programmes. ${ }^{4}$ In addition, several studies report that students' unprofessional behaviour at medical schools often precedes disciplinary action by medical boards as physicians. ${ }^{5,6}$ Parallels have also been found between the type of problematic behaviour in students and practising physicians. ${ }^{7}$

Until recently, two lines of thought on professionalism could be distinguished: professionalism as a trait, a personal characteristic or a feature of a student that is susceptible to development but hard to assess, and professional behaviour as the actual observable behaviour that can be assessed. ${ }^{8}$ Recently, the concept of 'Professional Identity Formation' (PIF) has been added to the discourse. ${ }^{9-15}$ PIF describes the process by which students are transformed from members of the lay public into skilled professionals. ${ }^{12,13}$ In this process, the student's underlying attitudes and virtues become increasingly visible in the student's actual (professional) behaviour. However, few tools are currently available to assess a student's progress towards the formation of a professional identity. ${ }^{14,15}$ Even when acknowledging that professionalism encompasses more than just behaviour, ${ }^{16}$ as the literature on PIF shows, a focus on unprofessional behaviour is still indispensable. ${ }^{17}$ Knowledge of the exact nature of unprofessional behaviour and the characteristics 
of students who behave unprofessionally can help to guide curriculum development, faculty development, the development of remediation strategies and future research. ${ }^{18}$ Thus far, many questions regarding the extent of occurrence, the exact nature and the risk factors of unprofessional behaviour among future doctors remain. ${ }^{18}$ Similar observations led Papadakis and colleagues to describe their research agenda for medical professionalism: they expressed the need to gather new evidence regarding demographics, ethnographics, and the epidemiology of lapses in professional behaviour. ${ }^{19}$ Prior to initiating tailor-made remediation practices for unprofessional behaviours, the exact nature of the unprofessional behaviour and the possible underlying causes should be studied. However, in many articles published on professionalism, the exact nature of unprofessional behaviour and student characteristics are rarely explicated. ${ }^{18,20,21}$ This study aims to describe the nature of the unprofessional behaviour displayed, as well as the characteristics of students referred to the professional behaviour board.

\section{Context of the study}

The current definition of professional behaviour used in all Dutch medical schools is 'the observable behaviour from which the norms and values of the medical professional can be visualised'. Professional and unprofessional behaviour is divided into three domains: dealing with oneself, dealing with others, and dealing with tasks/work (Table 1). ${ }^{22}$ At Leiden University Medical Center (LUMC), students who are judged to have behaved unprofessionally are referred to the professional behaviour board. The professional behaviour board, established in 2009, consists of 6 physicians, 1 midwife and 1 psychologist, all of whom are closely involved in the education of medical students. Lecturers, medical and paramedical personnel, as well as students' peers can refer a student to the professional behaviour board during his/her bachelor's and master's programme. The board discusses the referrals every fortnight and invites referred students to engage in debate with two members of the board. Subsequently, the board provides 'tailor-made' advice: a student may be advised, for example, to seek psychological support or to suspend his/her studies.

\section{Methods}

\section{Study design}

To gain more insight into the exact nature of the unprofessional behaviour displayed, as well as into the characteristics of referred students, a descriptive mixed methods approach was chosen. Qualitative data on the displayed unprofessional behaviour were collected from both the referral letters and the dossiers of the professional behaviour board. Quantitative data about the demographics of students were collected from the professional behaviour board dossiers and the student administration desk.

\section{Participants}

The total group of medical students enrolled in the bachelor's or master's programme at Leiden University during the study period between June 1, 2009 and January 1, 2014 consisted of 3410 students. In this study period, the board received 107 referrals concerning 93 students (3\% of a total of 3410 students). Eight students were referred twice, and 2 students were referred four times.

Consultation of the Medical Ethics Review Committee of the Leiden University Medical Center revealed that ethical approval was not needed for this study given the nature of the research, as all data were solely accessible by members of the professional behaviour board. The researchers who analysed the referral letters (PB and $\mathrm{JB}$ ) are both members of the professional behaviour board.

Table 1. Domains of professional behaviour and examples

\begin{tabular}{|c|c|}
\hline $\begin{array}{l}\text { Domains of } \\
\text { professional } \\
\text { behaviour }\end{array}$ & Examples \\
\hline \multirow[t]{4}{*}{$\begin{array}{l}\text { Dealing with } \\
\text { oneself }\end{array}$} & $\begin{array}{l}\text { Self-reflection: the student is able to reflect on his/her } \\
\text { self; is able to detect weak spots and is able to } \\
\text { formulate learning objectives }\end{array}$ \\
\hline & $\begin{array}{l}\text { Feedback: the student is open-minded when faced with } \\
\text { criticism and the right criticism does change his/her } \\
\text { behaviour }\end{array}$ \\
\hline & $\begin{array}{l}\text { Appearance: the student looks appropriate with regard } \\
\text { to clothing and hygiene during study meetings and } \\
\text { when dealing with patients }\end{array}$ \\
\hline & $\begin{array}{l}\text { Self-management: the student knows his/her tasks and } \\
\text { is able to set boundaries }\end{array}$ \\
\hline \multirow[t]{4}{*}{$\begin{array}{l}\text { Dealing with } \\
\text { others }\end{array}$} & $\begin{array}{l}\text { Verbal communication: the student communicates } \\
\text { proficiently in Dutch language }\end{array}$ \\
\hline & $\begin{array}{l}\text { Nonverbal communication: the student uses adequate } \\
\text { nonverbal language }\end{array}$ \\
\hline & $\begin{array}{l}\text { Cooperation: the student can act well in a group of staff, } \\
\text { peers and patients }\end{array}$ \\
\hline & $\begin{array}{l}\text { Privacy: the student protects confidential information } \\
\text { about patients and colleagues }\end{array}$ \\
\hline \multirow[t]{4}{*}{$\begin{array}{l}\text { Dealing with } \\
\text { tasks/work }\end{array}$} & $\begin{array}{l}\text { Responsibility: the student shows responsibility in } \\
\text { studying and in dealing with patients }\end{array}$ \\
\hline & $\begin{array}{l}\text { Time-management: the student performs his/her tasks } \\
\text { in an efficient way }\end{array}$ \\
\hline & $\begin{array}{l}\text { Independence: the student is able to make assignments } \\
\text { or deal with patient encounters without too much } \\
\text { support }\end{array}$ \\
\hline & Performance: the student is conscientious and punctual \\
\hline
\end{tabular}

\section{Data collection}

Data on gender, curricular phase when the referral was made, and nationality of the referred students were collected from the student administration desk. As only the country of birth of the students is registered, students were classified as non-Dutch if the official language of the country of birth on record was a language other than Dutch. Data on the reasons for referral and the number of referrals per student were collected from referral letters and professional behaviour board dossiers. 
In order to compare the referred students with the total student population, data on gender, nationality and phase in the curriculum of the total student population were also collected from the student administration desk.

\section{Data analysis}

First, one of the researchers (PB) analysed all referral letters, the professional behaviour board dossiers, and the distinct codes attached to every referral during the fortnightly meetings of the board. This code consists of the shortest possible summary of the reason for referral, recorded in the minutes. Hereafter, he categorised the reasons for referral into one or more of the domains of professional behaviour, according to the classification used in The Netherlands (dealing with oneself, dealing with others, and dealing with tasks/work; see Table 1). ${ }^{22-24}$ As the number of codes grew, the on-going process of renaming and reorganising codes resulted in a grouping of codes by themes. To monitor for inter-coder agreement another member of the research team (JB) independently repeated the categorisation for the first 2 years. The inter-coder agreement was found to be very high. Data on gender, nationality and curricular phase of the referred students were compared with the total student population.

\section{Results}

In the study period, the board received 107 referrals concerning 93 students (3\% of a total of 3410 students). Eight students were referred twice, and 2 students were referred four times.

\section{Characteristics of referred students}

Sixty-five of the 107 referrals (61\%) concerned male students. The distribution of male versus female at our medical school was fairly constant during the study period $(65 \%$ female). The odds of referral were 2.98 times higher for male students as compared to female students.

Thirty of the 107 referrals (28\%) concerned non-Dutch students. The percentage of students at our medical school who were born outside the Netherlands was relatively constant over the last four years at between $12 \%$ and $13 \%$. The odds of referral were 2.86 times higher for non-Dutch students compared to Dutch students.

Seventy-six referrals (71\%) occurred during the clinical rotations (Table 2).

\section{Nature of the unprofessional behaviour}

Sixty-five referrals concerned the domain 'dealing with others' $(61 \%)$, followed by the domain 'dealing with oneself, which saw 53 referrals (50\%). In 49 cases (46\%) the domain 'dealing with tasks' was at issue. For 56 referrals (52\%), the unprofessional behaviour consisted of a combination of two or three domains.

In the process of categorising the reasons for referral, four types of behaviour were recorded more than twice: 'withdrawn behaviour' (17 times), 'insufficient Dutch language proficiency' (14 times), 'impertinent emails' (9 times), and 'placing (privacy-sensitive) photos of the dissection room on the internet' (3 times) (see Table 2).

Table 2. Characteristics of the students referred to the professional behaviour board $(\mathrm{N}=107)$

\begin{tabular}{ll}
\hline Demographics & $\begin{array}{l}\text { Referrals } \\
\mathrm{N}(\%)\end{array}$ \\
\hline Female/Male & $\begin{array}{l}42 / 65(39 \% / 61 \%) \\
\text { Total student population } 65 \% / 35 \%\end{array}$ \\
Non-Dutch/Dutch & $\begin{array}{l}30 / 77(28 \% / 72 \%) \\
\text { Total student population } 12 \% / 88 \%\end{array}$ \\
Pre-clinical/Clinical & $\begin{array}{l}31 / 76(29 \% / 71 \%) \\
\text { Total student population } 50 \% / 50 \%\end{array}$ \\
Domains & \\
dealing with others & $65(61 \%)$ \\
dealing with tasks & $49(46 \%)$ \\
dealing with self & $53(50 \%)$ \\
combinations of domains & $56(52 \%)$
\end{tabular}

\section{Discussion}

This study is the first to analyse medical student referrals to a professional behaviour board in detail. It is also one of the few studies to describe the exact nature of concrete, observed unprofessional behaviour. ${ }^{18}$ The findings that men, non-Dutch minorities, and referrals from the clinical workplace dominate are pivotal for further research. Predominant reasons for referral such as 'withdrawn behaviour', 'insufficient Dutch language proficiency', 'impertinent emails', and 'placing privacy-sensitive photos on the internet' have already resulted in an adjustment of our information policy, in addition to specific remediation. Special effort should be made to clarify what faculty expects from students and teachers. ${ }^{25}$ The observations in this study can potentially guide future research, curriculum and faculty development and the development of remediation strategies. This will be elaborated in the sections below and discussed in light of the available literature.

\section{Characteristics of referred students}

\section{Male Students}

Male students' higher odds of getting referred raise the question of whether male students do indeed behave unprofessionally more often than female students do, or if a gender-specific bias exists in the likelihood of referral. Recent studies show gender differences in motivation, learning variables and learning outcomes. ${ }^{26,27}$ Male students have a significantly higher so-called 'controlled motivation' compared to female students. ${ }^{26}$ Controlled motivation represents motivation which is very low on selfdetermination. The more self-determined a student is, the 
better the observed outcomes with regards to deep learning, academic performance, adjustment, and well-being. ${ }^{26}$ Combined with the overrepresentation of male students among referrals, these findings raise the question of whether male students require different types of mentoring than female students. ${ }^{26}$ To answer this question, further (longitudinal) studies are needed.

\section{Non-Dutch Students}

Another group of overrepresented students were nonDutch students, a minority at the LUMC. There are a number of possible explanations for the underperformance of minorities. ${ }^{28,29}$ When considering unprofessional behaviour to be a form of underperformance, some of these explanations may also explain the overrepresentation of non-Dutch students in our study. First, a deficit in practical clinical knowledge may exist in students who belong to an ethnic minority. ${ }^{28}$ Second, (cultural) differences in communication styles may be a possible explanation for these students' underperformance. ${ }^{28} \mathrm{~A}$ third possible explanation is the so-called 'stereotype threat', which means that underperformance in ethnic groups could be caused by increased anxiety which arises in the student in response to the prospect of being negatively stereotyped. ${ }^{28}$ Finally, more subjective grading in clinical training can lead to what is called 'examiner bias', which means that examiners have a more positive view on people who are similar to themselves and who are believed to be a part of their own group than on people who do not to fall into those categories. ${ }^{28}$ In summary, Dutch examiners may mark Dutch students more highly than non-Dutch students for a variety of reasons. Future studies should be designed to address these hypotheses in the context of professional behaviour and medical education.

\section{Clinical Rotations}

The majority of referrals occurred during clinical rotations. Clinical rotations facilitate the observation of students and the assessment of their behaviour. However, it would be preferable to detect unprofessional behaviour earlier in a student's career, which would provide more opportunities for remediation. That is why longitudinal professionalism training was introduced as part of our curricular revision in 2012. This training consists of small working group sessions in which professionalism and communication training are discussed, as well as individual mentoring sessions in which academic progress and, if necessary, professional lapses are discussed. The first students enrolled in the new curriculum entered their master's programmes in June 2015. We are currently exploring how the new bachelor's programme has influenced the number and specifics of the referrals to the professional behaviour board.

\section{Nature of the unprofessional behaviour}

The referrals analysed are evenly distributed over the three domains dealing with oneself, dealing with others, and dealing with tasks/work. This subdivision in domains is useful to give the student more insight into the nature of their unprofessional behaviour, and will therefore guide remediation.

The remediation strategies of the four types of behaviour that were recorded more than twice will be described briefly. These four types of behaviour were 'withdrawn behaviour', 'insufficient Dutch language proficiency', 'sending impertinent emails' and 'placing privacy-sensitive photos on the internet'.

\section{Withdrawn behaviour}

Most students referred due to 'withdrawn behaviour' seemed to suffer from psychological problems such as depression or social anxiety disorders. These students were referred to a psychologist.

\section{Insufficient Dutch language proficiency}

The category 'insufficient Dutch language proficiency' consisted solely of non-Dutch students who could insufficiently express themselves in Dutch. These students were all advised to practice their Dutch or to take an intensive Dutch language course. More stringent selection criteria for admission to our medical school regarding Dutch language proficiency led to a decline in referrals for this reason.

\section{Impertinent emails}

A study on professional behaviour online was set up among students and teachers, as 'sending impertinent emails' is a frequent reason for referral, and because teachers and students seem to disagree on what is considered an impertinent email'. Based on the results of this study, a code of conduct for students has been created. This code will be addressed explicitly in a first-year lecture on professional behaviour.

\section{Privacy-sensitive photos}

Placing privacy-sensitive photos on the internet has ceased to be a reason for referral, as this too is now explicitly addressed at the beginning of the study program.

\section{Limitations and future directions}

This study has a number of limitations. First, the data were collected from only one institution, spanning a period of just 4.5 years, with a limited sample size (107 referrals from 93 different students). A study has already been set up into the nature of unprofessional behaviour and the characteristics of students who behave unprofessionally, using data from all eight Dutch medical schools. Preliminary data presented at meetings of the 'Netherlands Association for Medical Education Professionalism Think Tank' seem to 
reveal nationally comparable trends in the demographics and the epidemiology of lapses in professional behaviour. ${ }^{30}$ Another limitation of the current study is that not all referrals were documented in detail during the first years of the professional behaviour board. As teachers have since been trained in referring, nearly all referrals records are complete as of now.

Furthermore, there may be an underreporting of cases. In our study, $3 \%$ of all medical students were referred to the professional behaviour board, a figure which is comparable to other medical schools. ${ }^{31}$ However, as almost all cases reported undisputed unprofessional behaviour, it is likely that the referred $3 \%$ is only the tip of the iceberg. Teachers are indeed known to experience barriers in referring students. ${ }^{31-33}$ Unprofessional behaviour might be underreported for reasons similar to those of clinical lecturers who do not fail students. Dudek et al. identified four major barriers to failing trainees: '(1) lack of documentation, (2) lack of knowledge of what to specifically document, (3) anticipating an appeal process, and (4) lack of remediation options' ${ }^{34}$ These possible reasons for underreporting should be taken into account for faculty development. Recent research by Mak-van der Vossen et al. indicates that supporting teachers in assessing professional behaviour and involving them in the remediation of unprofessional behaviour helps to overcome these barriers. ${ }^{31}$

Finally, for privacy reasons only the country of birth of students was available. In legal terms, a person is considered "Dutch native" (autochthonous) when both parents are born in the Netherlands. Students were classified as nonDutch if the official language of their country of birth was a language other than Dutch. However, country of birth is not a perfectly accurate way of identifying non-Dutch students, which is why this study likely underreports the number of non-Dutch students.

\section{Conclusions}

Knowledge of the exact nature of displayed unprofessional behaviour and the characteristics of students referred to a professional behaviour board is needed to guide curriculum development, faculty development, the development of remediation strategies and future research. Although only a minority of students is referred to a professional behaviour board, our study shows that student characteristics such as gender and nationality may correlate to a higher incidence of unprofessional behaviour. Further explanatory and exploratory research is needed to unravel this relationship, and to study the influence of curriculum reforms on these relationships, respectively.

\section{Conflict of Interest}

The authors declare that they have no conflict of interest.

\section{References}

1. Langendyk V, Mason G, Wang S. How do medical educators design a curriculum that facilitates student learning about professionalism? Int J Med Educ. 2016;7:32-43.

2. Passi V, Doug M, Peile E, Thistlethwaite J, Johnson N. Developing medical professionalism in future doctors: a systematic review. Int J Med Educ. 2010;1:19-29.

3. Ziring D, Danoff D, Grosseman S, Langer D, Esposito A, Jan MK, et al. How do medical schools identify and remediate professionalism lapses in medical students? A study of US and Canadian medical schools. Acad Med. 2015;90(7):913-20.

4. Royal College of Physicians and Surgeons in Canada. The CanMEDS 2015 [cited 12 March 2016]; Available from: http://www.royalcollege.ca /portal/page/portal/rc/canmeds/canmeds2015.

5. Papadakis MA, Hodgson CS, Teherani A, Kohatsu ND. Unprofessional behavior in medical school is associated with subsequent disciplinary action by a state medical board. Acad Med.2004;79(3):244-9.

6. Papadakis MA, Teherani A, Banach MA, Knettler TR, Rattner SL, Stern DT, et al. Disciplinary action by medical boards and prior behavior in medical school. N Engl J Med. 2005;353(25):2673-82.

7. Ainsworth MA, Szauter KM. Medical student professionalism: are we measuring the right behaviors? A comparison of professional lapses by students and physicians. Acad Med. 2006;81(10 Suppl):S83-6.

8. Barnhoorn PC. What does a professionalism assessment scale measure? Int J Med Educ. 2015;6:62.

9. Monrouxe LV. Identity, identification and medical education: why should we care? Med Educ. 2010;44(1):40-9.

10. Monrouxe LV, Rees $\mathrm{CE}, \mathrm{Hu}$ W. Differences in medical students' explicit discourses of professionalism: acting, representing, becoming. Med Educ. 2011;45(6):585-602.

11. Wong A, Trollope-Kumar K. Reflections: an inquiry into medical students' professional identity formation. Med Educ. 2014;48(5):489-501.

12. Cruess RL, Cruess SR, Boudreau JD, Snell L, Steinert Y. Reframing medical education to support professional identity formation. Acad Med. 2014;89(11):1446-51.

13. Cruess RL, Cruess SR, Boudreau JD, Snell L, Steinert Y. A Schematic representation of the professional identity formation and socialization of medical students and residents: a guide for medical educators. Acad Med. 2015; 90(6):718-25.

14. Cruess RL, Cruess SR, Steinert Y. Amending Miller's pyramid to include professional identity formation. Acad Med. 2016;91(2):180-5.

15. Barnhoorn PC. Professional identity formation: onions rather than pyramids. Acad Med. 2016;91(3):291.

16. Brody H, Doukas D. Professionalism: a framework to guide medical education. Med Educ. 2014;48(10):980-7.

17. Barnhoorn PC, van Mook WN. Professionalism or professional behaviour: no reason to choose between the two. Med Educ. 2015;49(7):740.

18. Fargen KM, Drolet BC, Philibert I. Unprofessional behaviors among tomorrow's physicians: review of the literature with a focus on risk factors, temporal trends, and future directions. Acad Med. 2016;91(6):858-64.

19. Papadakis MA, Paauw DS, Hafferty FW, Shapiro J, Byyny RL. Perspective: the education community must develop best practices informed by evidence-based research to remediate lapses of professionalism. Acad Med. 2012;87(12):1694-8.

20. Braatvedt C, Poole P, Merry A, Gorman D, Reid P, Bagg W. Fitness to practice of medical graduates: one programme's approach. N Z Med J. 2014;127(1405):70-7.

21. Yates J. "Concerns" about medical students' adverse behaviour and attitude: an audit of practice at Nottingham, with mapping to GMC guidance. BMC Med Educ. 2014;14:196.

22. van Luijk SJ, Smeets JGE, Smits J, Wolfhagen I, Perquin MLF. Assessing professional behaviour and the role of academic advice at the Maastricht Medical School. Med Teach. 2000;22(2):168-72.

23. van Mook WN, van Luijk SJ, van der Vleuten CP. Professional behaviour during medical training. Ned Tijdschr Geneeskd. 2009;153:A542. 
24. van Luijk S, van Santen-Hoeufft M, Hillen H, Smeets J. Het beoordelen van professioneel gedrag bij studenten en artsen. Tijdschrift voor Medisch Onderwijs. 2000;19(5):163-71.

25. Cruess RL, Cruess SR, Steinert Y. Teaching medical professionalism: Cambridge University Press; 2008.

26. Kusurkar RA, Croiset G, Galindo-Garre F, Ten Cate O. Motivational profiles of medical students: association with study effort, academic performance and exhaustion. BMC Med Educ. 2013;13:87.

27. Kusurkar RA, Ten Cate TJ, Vos CM, Westers P, Croiset G. How motivation affects academic performance: a structural equation modelling analysis. Adv Health Sci Educ Theory Pract. 2013;18(1):57-69.

28. Stegers-Jager KM, Steyerberg EW, Cohen-Schotanus J, Themmen AP. Ethnic disparities in undergraduate pre-clinical and clinical performance. Med Educ. 2012;46(6):575-85

29. Esmail A, Roberts C. Academic performance of ethnic minority candidates and discrimination in the MRCGP examinations between 2010 and 2012: analysis of data. BMJ. 2013;347:f5662.

30. van Mook W, van Luijk S, Fey-Schoenmakers M, Oudhuis G, Gulikers $\mathrm{M}$, Schuwirth L, et al. Bespreking en beoordeling van professioneel gedrag aan de Faculteit Geneeskunde te Maastricht. Tijdschrift voor Medisch Onderwijs. 2007;26(5):181-7.

31. Mak-van der Vossen M, Peerdeman S, van Mook W, Croiset G Kusurkar R. Assessing professional behaviour: Overcoming teachers' reluctance to fail students. BMC Res Notes. 2014;7:368

32. de Oliveira Vidal EI, Silva Vdos S, Santos MF, Jacinto AF, Boas PJ, Fukushima FB. Why medical schools are tolerant of unethical behavior Ann Fam Med. 2015;13(2):176-80.

33. Rougas S, Gentilesco B, Green E, Flores L. Twelve tips for addressing medical student and resident physician lapses in professionalism. Med Teach. 2015;37(10):901-7.

34. Dudek NL, Marks MB, Regehr G. Failure to fail: the perspectives of clinical supervisors. Acad Med. 2005;80(10 Suppl):84-7. 